\title{
Nerve Growth Factor Stimulates the Accumulation of $\beta 1$ Integrin at the Tips of Filopodia in the Growth Cones of Sympathetic Neurons
}

\author{
Peter W. Grabham and Daniel J. Goldberg \\ Department of Pharmacology and Center for Neurobiology and Behavior, Columbia University, New York, \\ New York 10032
}

\begin{abstract}
Addition of nerve growth factor (NGF) to sympathetic neurons that have been starved of it causes a rapid induction of growth cone motility and the resumption of neurite growth. Using immunofluorescence staining, we show that within $10 \mathrm{~min}$, NGF stimulated the accumulation of dense aggregates of $\beta 1$ integrin [a receptor for extracellular matrix (ECM) proteins] at most of the tips of either newly extended or preexisting filopodia. This effect occurred in the absence of ECM proteins and in the presence of $1 \mathrm{mg} / \mathrm{ml}$ Arg-Gly-Asp-Ser peptide, which blocks ECM binding to integrin, indicating that occupation of the integrin receptor is not necessary for tip localization. In fact, addition of either laminin or fibronectin caused a rapid withdrawal of $\beta 1$ integrin aggregates from filopodial tips at a rate comparable to that of the rearward flow of actin filaments in the periphery of
\end{abstract}

the growth cone. Surface labeling of the extracellular domain of $\beta 1$ integrin while aggregated at the tips of filopodia or withdrawing in response to ECM proteins showed that the receptor is positioned within the membrane. The drug butanedione monoxime, an inhibitor of myosins, blocked the accumulation of $\beta 1$ integrin at the tips of filopodia without inhibiting the formation of filo-podia, suggesting the involvement of a myosin motor in $\beta 1$ integrin transport. These results provide the first evidence of NGF-mediated accumulation of ECM receptors to sensory elements of the growth cone and suggest one mechanism whereby soluble and substrate-bound cues coordinate to produce directed neurite growth.

Key words: nerve growth factor; $\beta 1$ integrin; sympathetic neuron; growth cone; filopodium; extracellular matrix
The rate and direction of neurite growth are tightly regulated by external cues: positive and negative, soluble and surface-bound, cellular and acellular (Baier and Bonhoeffer, 1994; Goodman, 1996; Tessier-Lavigne and Goodman, 1996). The motile growth cone at the end of the growing neurite is a prime target for these cues; changes in growth cone behavior cause changes in neurite growth (Kapfhammer and Raper, 1987; O'Connor et al., 1990; Rivas et al., 1992; Lin and Forscher, 1995). The digitate filopodia, which can project many micrometers forward from the body of the growth cone, are particularly important (Bentley and ToroianRaymond, 1986; Caudy and Bentley, 1986; Hammarback and Letourneau, 1986; Bandtlow et al., 1990; Zheng et al., 1996).

Nerve growth factor (NGF) is a widely studied soluble promoter of neurite growth. A member of the family of neurotrophins, it promotes neurite growth from sympathetic neurons, some primary sensory neurons, and, probably, from certain neurons in the CNS (Levi-Montalcini, 1987). The promotion of neurite growth is effected by binding of NGF to the trkA receptor, an integral membrane protein tyrosine kinase (Loeb et al., 1991).

Laminin 1 [mouse Engelbroth-Holm-Swarm (EHS) laminin] and fibronectin promote neurite growth as surface-bound proteins. They are abundant in the extracellular matrix (ECM); ECM proteins can also be found on the surface of certain cells

Received Feb. 19, 1997; revised April 30, 1997; accepted May 8, 1997.

This work was supported by National Institutes of Health Grants NS25161 and GM32099. We thank Drs. C. Buck, C. Bulinski, and M. Willard for their generous gifts of antibodies, Drs. K. Yamada and A. Horwitz for the ES66-8 hybridoma cell line, Rachel Yarmolinsky and Eve Vagg for image processing and photography, and Thu V. Chu for blind studies.

Correspondence should be addressed to Dr. Peter W. Grabham, Department of Pharmacology, Columbia University, 630 West 168th Street, New York, NY 10032 Copyright (C) 1997 Society for Neuroscience $0270-6474 / 97 / 175455-11 \$ 05.00 / 0$ that form pathways for neurite growth (Rogers et al., 1986; Bixby et al., 1988; Reichardt and Tomaselli, 1991). Laminin 1 and fibronectin on the substrate in culture dishes promote neurite growth from a variety of vertebrate neurons, including sensory and sympathetic neurons (Baron-van Evercooren et al., 1982; Rogers et al., 1983), by binding to integrin receptors, heterodimeric integral membrane proteins (Bozyczko and Horwitz, 1986; Tomaselli et al., 1987; Reichardt and Tomaselli, 1991; Hynes, 1992). The integrins that mediate the promotion of neurite growth by these ECM proteins contain the $\beta 1$ subunit (Bozyczko and Horwitz, 1986; Tomaselli et al., 1987; Tomaselli et al., 1990; Reichardt and Tomaselli, 1991).

Thus, process outgrowth from certain types of neurons, such as sympathetic and primary sensory neurons, is stimulated both by the soluble neurotrophins and the substrate-bound ECM proteins. The mechanisms by which these molecules act rapidly and locally on the growth cone to stimulate elongation seem to differ, however. Whereas NGF stimulates actin-based protrusive and motile activities (Seeley and Greene, 1983; Aletta and Greene, 1988), laminin 1 facilitates the advancement of microtubules and membrane-bound organelles into protrusive structures to begin their conversion into new neuritic length (Rivas et al., 1992).

Growth cones are subject to multiple environmental cues as they navigate (Goodman, 1996). There may be an element of redundancy to provide a safety margin for correct guidance. But, also, there may be combinatorial effects, which could greatly increase the information supplied by a limited number of guidance molecules (Goodman, 1996). Some long-term interactions between different types of cues have been described. For example, treatment of PC12 cells with NGF increases the expression of integrin at the surface over a period of days (Zhang et al., 1993). We describe here a novel type of short-term interaction in which 
NGF rapidly causes the accumulation of $\beta 1$ integrin at the tips of filopodia of sympathetic growth cones. Thus, the soluble neurotrophin regulates the presentation of the ECM receptor to the environment, moving it rapidly to where it may be able to interact more effectively with surface-bound ligand.

\section{MATERIALS AND METHODS}

Materials. 2,3-Butanedione monoxime (BDM), Arg-Gly-Asp-Ser (RGDS) peptide, fibronectin from bovine plasma, cytochalasin $\mathrm{D}$, anti-talin monoclonal antibody (8d4), and anti- $\beta 1$ integrin (W1B10) and anti-vinculin (human VIN-1) monoclonal antibodies were obtained from Sigma (St. Louis, MO). NGF and laminin 1 (from mouse EHS sarcoma) were from Boehringer Mannheim (Indianapolis, IN). Texas Red-phalloidin was obtained from Molecular Probes (Eugene, OR). Chickie II anti- $\beta 1$ integrin polyclonal antibody was a gift from Dr. C. Buck (Wistar Institute, Philadelphia, PA), G2 anti-actin polyclonal antibody was a gift from Dr. J. C. Bulinski (Columbia University, New York, NY), and anti-growthassociated protein (GAP)-43 polyclonal antibody was a gift from Dr. M. Willard (Washington University, St. Louis, MO). ES66-8 rat hybridoma cells were generously provided by Drs. K. M. Yamada (National Institutes of Health, Bethesda, MD) and A. F. Horwitz (University of Illinois, Urbana, IL). ES66 is a monoclonal antibody directed against chicken $\beta 1$ integrin, which does not block function. The antibody was purified from hybridoma supernatants by ammonium sulfate precipitation, followed by anion exchange chromatography (Duband et al., 1988).

Cell culture. Sympathetic ganglia were dissected from embryonic day 10-13 chick embryos, washed in HBSS, and dissociated by using $0.25 \%$ trypsin for $10 \mathrm{~min}$ at $37^{\circ} \mathrm{C}$. After pelleting, cells were plated onto coverslips precoated with $50 \mu \mathrm{g} / \mathrm{ml}$ poly-D-lysine and $50 \mu \mathrm{g} / \mathrm{ml}$ poly-Lornithine in $0.1 \mathrm{M}$ sodium borate, $\mathrm{pH}$ 8.0. To allow the use of larger sample numbers with parallel conditions, multiwell dishes with coverslips glued to the underside were used. Coverslips were preincubated with RPMI 1640 medium containing 10\% heat-inactivated horse serum for 2 $\mathrm{hr}$ at $37^{\circ} \mathrm{C}$, and cells were incubated in $\mathrm{L} 15$ medium supplemented with $10 \%$ fetal bovine serum, glutamine, and $50 \mathrm{ng} / \mathrm{ml} \mathrm{NGF}$. For cultures in which filopodia are already present after NGF starvation, coverslips were preincubated in serum-free defined medium (L15 supplemented with $2 \%$ BSA, glutamine, $10 \mu \mathrm{g} / \mathrm{ml}$ transferrin, $5 \mu \mathrm{g} / \mathrm{ml}$ insulin, $5 \mathrm{ng} / \mathrm{ml}$ sodium selenite, and $100 \mathrm{~mm}$ sodium pyruvate), and cells were cultured in the same medium plus $50 \mathrm{ng} / \mathrm{ml} \mathrm{NGF}$. After $13-15 \mathrm{hr}$ of incubation at $37^{\circ} \mathrm{C}$ in $5 \% \mathrm{CO}_{2}$, quiescence of growth cones was induced by removal of NGF and other serum factors. For both culture types, $5 \mathrm{ml}$ of medium was replaced every $30 \mathrm{~min}$ with serum-free defined medium for the first hour and then every hour for $4-5 \mathrm{hr}$ (serum-supplemented cultures) or $6-8 \mathrm{hr}$ (serum-free cultures), and then with L15 alone for the last hour (both types of cultures). NGF and other reagents were added to individual wells after aspiration of the last wash. All experiments were performed at $37^{\circ} \mathrm{C}$. Cultures were determined to be $>80 \%$ neurons as shown by immunoreactivity to GAP-43.

Immunocytochemistry. Cells were fixed by the addition of $5 \mathrm{ml}$ of PBS, $\mathrm{pH} 7.4$, containing $4 \%$ paraformaldehyde, $0.1 \%$ glutaraldehyde, and 400 $\mathrm{mM}$ sucrose for $5 \mathrm{~min}$ at $37^{\circ} \mathrm{C}$, followed by one rinse and three $5 \mathrm{~min}$ washes in PBS and $0.15 \%$ Triton X-100. After blocking with $10 \%$ normal goat serum (NGS) in PBS and $0.15 \%$ Triton X-100 for $30 \mathrm{~min}$ at room temperature (rt), cells were incubated in either a 1:100 dilution (polyclonal antiserum) or a $5-10 \mu \mathrm{g} / \mathrm{ml}$ concentration (monoclonal antibodies) of primary antibody diluted in PBS/1\% NGS and $0.015 \%$ Triton $\mathrm{X}-100$. Incubation times were either $1 \mathrm{hr}$ at $\mathrm{rt}$ (anti-actin and anti-GAP43 ) or overnight at $4^{\circ} \mathrm{C}$ (anti- $\beta 1$ integrin, anti-vinculin, and anti-talin). For double staining, primary antibodies were applied consecutively. Cells were then washed in PBS and incubated in a fluorescenceconjugated secondary antibody diluted 1:100 in PBS/1\% NGS for $1 \mathrm{hr}$ at rt. For most analyses, cells were double-stained with Chickie II anti- $\beta 1$ integrin followed by fluorescein-conjugated anti-rabbit IgG and $0.33 \mu \mathrm{M}$ Texas Red-phalloidin. Controls included replacement of the primary antibody with normal serum. To confirm staining of actin and $\beta 1$ integrin, we stained with the anti- $\beta 1$ integrin monoclonal antibody (W1B10) and then the anti-actin polyclonal antibody (G2), followed by a mixture of Texas Red-mouse IgG and fluorescein-rabbit IgG. After a final wash in PBS, cells were mounted in $20 \mathrm{mg} / \mathrm{ml}$ propyl gallate in $90 \%$ glycerol/ $10 \%$ PBS. For surface staining of $\beta 1$ integrin, cells were fixed without detergent extraction, quenched by incubation in $0.1 \mathrm{M}$ glycine/PBS for 5 min at $\mathrm{rt}$, and then stained for $\beta 1$ integrin (using W1B10) as described above.
Analysis of formation of filopodia and integrin accumulation at tips. Analyses were performed on cultures double-stained for $\beta 1$ integrin and F-actin and viewed using filter sets that visualized fluorescein alone, Texas Red alone, or both simultaneously (Omega Optical, Brattleboro, VA). Tip staining of $\beta 1$ integrin was seen as green fluorescence at the tip of a Texas Red-phalloidin-stained filopodium. Any $\beta 1$ integrin aggregates slightly behind the tips were recognized against the F-actin stain and scored negative. To determine whether tip staining was an artifact attributable to swelling of filopodial tips, unconjugated Texas Red was used to label proteins indiscriminately (Coates et al., 1992). More than $95 \%$ of tips were seen to terminate without swelling. Tip staining was also assessed in a blind study using silicon intensified target camera images. Digitized images of growth cones stained for $\beta 1$ integrin and Texas Red were thresholded for pixel brightness with a lower limit that included all lamellipodial regions. Those filopodia with tips but not shafts that exceeded the threshold limit were scored positive. After 10 min of NGF treatment, $87 \%$ of tips scored positive with anti- $\beta 1$ integrin (Chickie II) staining compared with none with Texas Red. Threshold counts were comparable to manual counts. Counts were therefore made manually by traversing the stained culture and scoring both numbers of filopodia and tip staining or tip staining alone (see Fig. $3 A, B$ ). For values per growth cone, at least 100 growth cones were scored, and SDs were calculated. For values as percentages, at least 200 filopodia were scored. For the determination of $\beta 1$ integrin aggregates in the distal and proximal halves of growth cones, at least 25 growth cones were scored. Statistical $t$ tests using the Bonferroni method for multiple comparisons (Wallenstein et al., 1980) were performed when appropriate.

\section{RESULTS}

\section{Changes in the organization of actin and the localization of $\beta 1$ integrin induced by readdition of NGF}

Withdrawal and subsequent readdition of NGF to cultures of sympathetic neurons produces a change in growth cones from a nonmotile, club-shaped phenotype to a highly motile structure with filopodia and ruffling membranes (Seeley and Greene, 1983; Aletta and Greene, 1988). In the present study, we used double immunofluorescence staining of fixed chick embryonic sympathetic neurons to visualize changes in the actin cytoskeleton and the distribution of $\beta 1$ integrin during the onset of motility. Although growth cones exhibit much variation within a culture, NGF withdrawal concomitant with a sequential elimination of other trophic factors on a poly-D-lysine/poly-L-ornithine substrate resulted in a synchronization of morphology that enabled us to quantitate analysis of events after the readdition of NGF.

The distribution of $\mathrm{F}$-actin and $\beta 1$ integrin in a typical quiescent growth cone is shown in Figure 1, $A$ and $B$. The growth cone is club-shaped and has few remaining filopodia (mean number \pm $\mathrm{SD}$ of filopodia per growth cone, $1.9 \pm 1.9$ ). F-actin, visualized by staining with Texas Red-phalloidin, is mostly arranged diff usely in the peripheral region, with some small dense aggregates. $\beta 1$ Integrin, visualized by staining with a polyclonal antibody, is distributed diffusely throughout the growth cone. One minute after the readdition of $100 \mathrm{ng} / \mathrm{ml} \mathrm{NGF}$, intensely stained patches of F-actin appeared close to the leading edge of the growth cone (Fig. $1 C$ ). $\beta 1$ Integrin was also concentrated in some of these patches (Fig. 1D). Many smaller aggregates of F-actin did not contain $\beta 1$ integrin. By 3 min after addition of NGF, numerous filopodia had extended, and F-actin patches were larger and fused into a band filling the peripheral region of the growth cone (Fig. $1 E)$ Some aggregates of $\beta 1$ integrin remained in this region, but much was distributed along newly formed filopodia (Fig. $1 F$ ). Filopodia continued to extend during the next few min until, by 10 min after addition of NGF, growth cones had an average of $15.5 \pm 2.6$ filopodia, and $\beta 1$ integrin was concentrated at the tips of most of them (Fig. 1G-I). This was confirmed by additional double staining with an antibody that recognizes actin (G2) and 

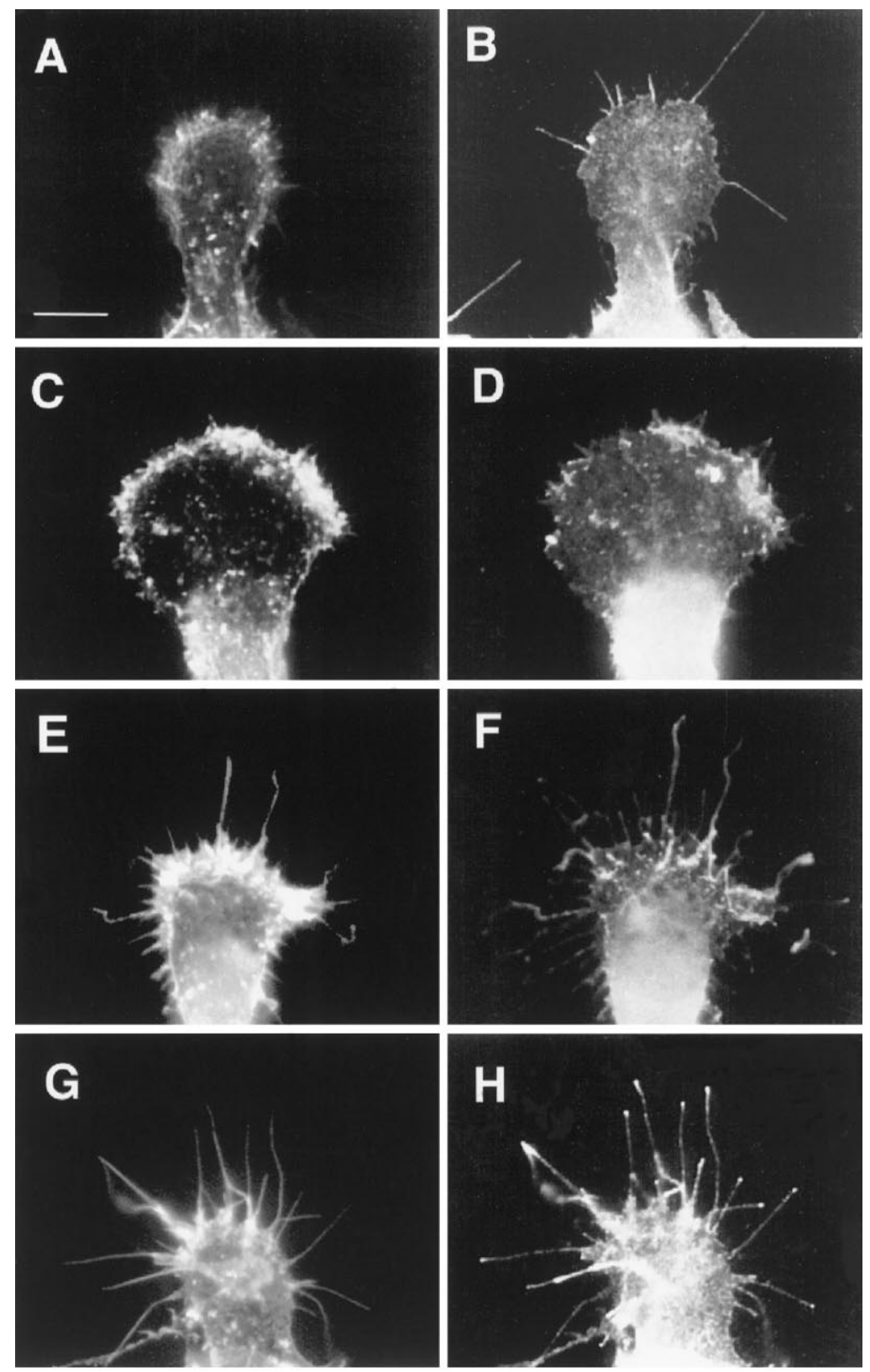

I

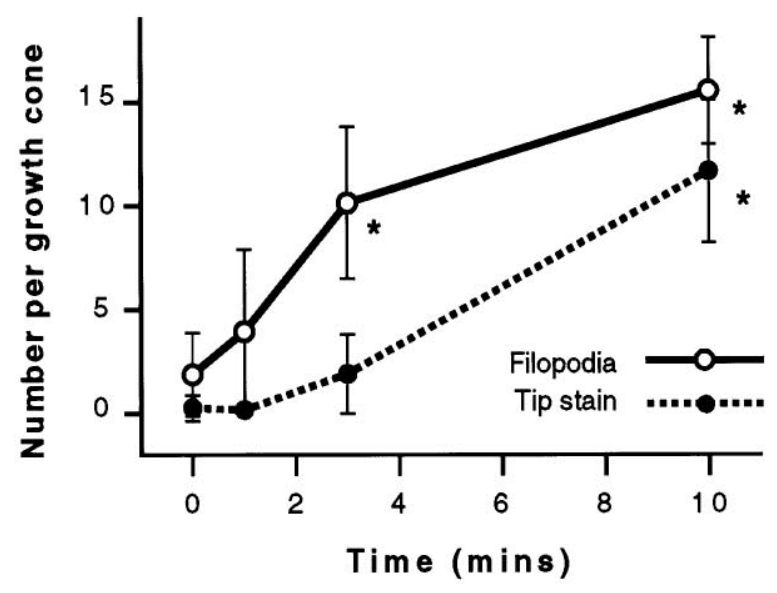

Figure 1. NGF rapidly induces the formation of filopodia and the accumulation of $\beta 1$ integrin at filopodial tips. Representative growth cones were fixed at various times after addition of $100 \mathrm{ng} / \mathrm{ml} \mathrm{NGF}$ and double-stained for detection of F-actin and $\beta 1$ integrin by fluorescence microscopy. Left panels show F-actin, and right panels show $\beta 1$ integrin. $A, B$, The growth cone has few filopodia, and $\beta 1$ integrin is distributed unremarkably before NGF is added. $C, D$, One minute after the addition of NGF, patches of F-actin and $\beta 1$ integrin appear close to the leading edge of the growth cone. $E, F$, Filopodia have begun to extend by 3 min after the addition of NGF. $\beta 1$ Integrin can be found in extending filopodia. $G, H$, By $10 \mathrm{~min}$, filopodia have fully extended, and $\beta 1$ integrin is concentrated at the tips. Scale bar in $A, 10 \mu \mathrm{m}$. I, Quantitation of the number of filopodia (solid line) and accumulation of $\beta 1$ integrin (broken line) at filopodial tips per growth cone after addition of NGF. The appearance of tip aggregates lags somewhat behind the formation of filopodia. Values are representative of three separate experiments. Sample number $=100$. Error bars show SDs. Asterisks denote those values that are significantly different $(p<0.005)$ from control $(0$ min) values. 

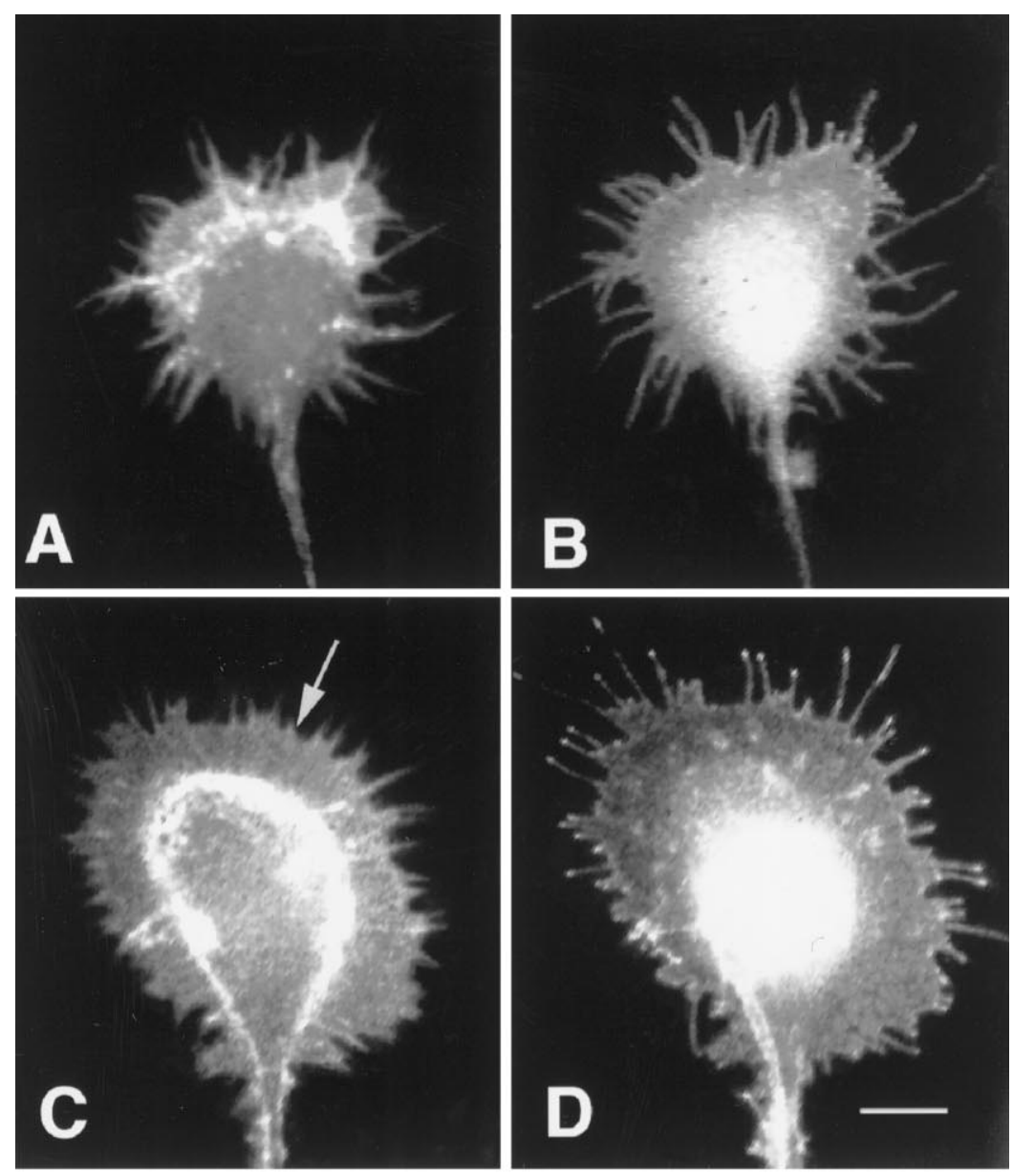

Figure 2. Accumulation of $\beta 1$ integrin at filopodial tips is not dependent on the extension of filopodia. $A, B$, Representative growth cone that had been cultured in serum-free conditions, starved of NGF, and double-stained for F-actin $(A)$ and $\beta 1$ integrin $(B)$. Filopodia are present, and $\beta 1$ integrin is distributed evenly along their length. $C, D$, Representative growth cone cultured as in $A$ and $B$, treated with $100 \mathrm{ng} / \mathrm{ml} \mathrm{NGF}$ for $10 \mathrm{~min}$, and double-stained for F-actin $(C)$ and $\beta 1$ integrin $(D)$. Numerous veils have extended $(C$, arrow), and filopodia show accumulation of $\beta 1$ integrin at their tips. Scale bar in $D, 10 \mu \mathrm{m}$. E, Quantitation of the accumulation of $\beta 1$ integrin at filopodial tips. Although the number of filopodia per growth cone remains constant, the number of tips with concentrations of $\beta 1$ integrin increases after treatment with NGF. Results are representative of three separate experiments $(n=100)$. Error bars show SDs. Asterisks denote those values that are significantly different $(p<$ 0.005 ) from control ( $0 \mathrm{~min})$ values for tip staining.

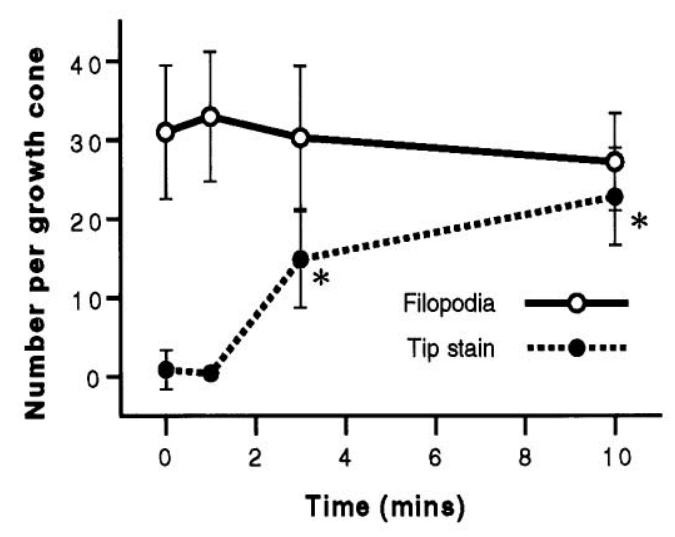

a second anti- $\beta 1$ integrin antibody (W1B10). The focal adhesion proteins, vinculin and talin, did not co-localize with $\beta 1$ integrin at the tips of filopodia, although we did detect these proteins colocalized with the patches of $\beta 1$ integrin that appeared in the peripheral region after 1 min of NGF treatment (data not shown).

\section{Accumulation of $\beta 1$ integrin at filopodial tips is not dependent on filopodial extension}

A potential mechanism by which $\beta 1$ integrin becomes localized to filopodial tips is one in which aggregates of the receptor are situated in the early ( $1 \mathrm{~min}) \mathrm{F}$-actin aggregates such that they can then "ride" out on the tips of extending filopodia. We investigated this possibility by exploiting a different manipulation of the culturing conditions, which allows the retention of filopodia in the absence of NGF. This was achieved by culturing cells in a serumfree medium. Before removal of NGF, 53\% of filopodia showed aggregates of $\beta 1$ integrin. The distribution of F-actin and $\beta 1$ integrin in a typical growth cone several hours after removal of NGF is shown in Figure $2, A$ and $B$. There are numerous filopodia, and F-actin is organized not only diffusely but also in dense aggregates in the rear of the peripheral region and in the cores of some filopodia. $\beta 1$ Integrin, however, is again distributed evenly in the peripheral region of the growth cone, with some concentration at the leading edge but no appreciable aggregation at filopodial tips. Readdition of NGF resulted in the extension of veils of membrane rather than filopodia (Fig. $2 C$ ); in fact, the mean number of filopodia remained at $\sim 30$ per growth cone (Fig. 
$2 E$ ). Moreover, the appearance of patches of F-actin and $\beta 1$ integrin was not observed at the leading edge of the growth cone 1 min after the addition of NGF (data not shown), as seen in cells that had been initially cultured in serum. $\beta 1$ Integrin did, however, rapidly accumulate at the tips of filopodia (Fig. $2 D$ ). Indeed, tip staining increased dramatically from an average of $0.9 \pm 2.5$ to $22.8 \pm 6.2$ stained tips per growth cone (Fig. $2 E$ ). It is possible that instead of $\beta 1$ integrin accumulating at filopodial tips it is already present, and NGF is causing an antigenic site on the ECM receptor to become unmasked. However, additional double staining with the anti-actin polyclonal antibody and two monoclonal antibodies that recognize separate sites on the extracellular domain of $\beta 1$ integrin (W1B10 and ES66) showed a similar staining pattern, suggesting that this is not the case.

Although the localization of $\beta 1$ integrin to tips was not dependent on the formation of new filopodia, we found that it was sensitive to the action of the F-actin-destabilizing drug cytochalasin D. Growth cones were treated for $5 \mathrm{~min}$ before the addition of NGF with a concentration of cytochalasin D $(1 \mu \mathrm{M})$ that is sufficient to prevent actin polymerization without greatly disrupting existing filopodia (Wu et al., 1996). Under these conditions, only $9 \%$ of filopodia showed integrin tip aggregates compared with $68 \%$ in control cultures.

\section{Effect of ECM proteins on the accumulation of $\beta 1$ integrin at filopodial tips}

The culture procedure described in the previous section permitted the detection and quantitation of the accumulation of $\beta 1$ integrin at the tips of filopodia in the absence of added serum or purified ECM proteins. We therefore used this paradigm to determine the effects of ECM proteins on three aspects of $\beta 1$ integrin relocalization: first, to see whether ECM proteins can induce $\beta 1$ integrin tip accumulation independently of NGF; second, to confirm that ECM proteins are not necessary for NGF to induce tip accumulation of $\beta 1$ integrin; and third, to determine the effect of ECM proteins on $\beta 1$ integrin that had previously accumulated at filopodial tips in response to NGF.

ECM proteins did not cause $\beta 1$ integrin to accumulate at the tips of filopodia. Addition of either $20 \mu \mathrm{g} / \mathrm{ml}$ fibronectin or 20 $\mu \mathrm{g} / \mathrm{ml}$ laminin 1 to NGF-starved neurons resulted in an accumulation of $\beta 1$ integrin tip aggregates no greater than the control $(<2 \%$ of the tips had aggregates after $10 \mathrm{~min}$, compared with $74 \%$ in paired dishes to which NGF alone was readded) (data not shown).

Although there was no addition of serum or ECM proteins to the culture medium or the substrate in this protocol, we could not be sure that ECM proteins were not present, either in residual amounts from the dissociation of the original ganglionic tissue or secreted by cells in culture. We therefore examined NGFmediated tip localization in the presence of $1 \mathrm{mg} / \mathrm{ml}$ RGDS peptide, which blocks the binding of ECM proteins such as fibronectin and vitronectin to $\beta 1$ integrin. The rate and extent of tip accumulation of $\beta 1$ integrin were unaffected by the RGDS peptide (Fig. 3A). After 10 min of NGF treatment, 64\% of filopodial tips showed $\beta 1$ integrin aggregates, compared with $67 \%$ in the presence of RGDS, providing more evidence that occupancy of $\beta 1$ integrin by ECM proteins is not necessary for tip accumulation to be induced by NGF.

In parallel dishes of the same experiment, we added $20 \mu \mathrm{g} / \mathrm{ml}$ fibronectin to cells that had been treated with NGF for $10 \mathrm{~min}$. The ECM protein stimulated a rapid reduction in the number of tip aggregates (Fig. 3A). The percentage of filopodial tips with aggregates of $\beta 1$ integrin was nearly halved within $1 \mathrm{~min}$, and, by $10 \mathrm{~min}$, only $16 \%$ of the tips displayed aggregates. Interestingly, as the tip staining reduced, we observed distinct aggregates of $\beta 1$ integrin situated proximally along the length of the filopodia. RGDS peptide inhibited the action of fibronectin; in the presence of the peptide, the percentage of tips with aggregates remained at around 60 for the $10 \mathrm{~min}$ after addition of fibronectin. Laminin 1 had the same effect as fibronectin. Figure $3 B$ shows the effect of laminin 1 on $\beta 1$ integrin previously aggregated at filopodial tips. As seen with fibronectin, laminin 1 caused a rapid reduction in tips with aggregates of $\beta 1$ integrin. In $1 \mathrm{~min}$, the percentage of tips with aggregates decreased from 60 to 25 , and by $5 \mathrm{~min}$ it had reached a basal level of $11 \%$.

The appearance of distinct aggregates of $\beta 1$ integrin situated along the length of filopodia (Fig. $3 C$ ) suggests that laminin 1 and fibronectin cause the aggregates of $\beta 1$ integrin to migrate toward the central region of the growth cone. We examined this possibility by counting the number of aggregates of $\beta 1$ integrin at the tip and in the proximal and distal halves (excluding the tip) of each filopodium during the first 5 min after addition of laminin 1 . As the mean number of tip aggregates per growth cone decreased from $9.0 \pm 2.9$ to $5.5 \pm 1.4$ during the first $2 \mathrm{~min}$, the mean number of distal aggregates increased from $1.3 \pm 0.4$ to $4.7 \pm 1.2$ (Fig. 3D). Between 2 and 5 min proximal aggregates became most numerous, increasing from $0.9 \pm 0.6$ to $4.7 \pm 1.1$ per growth cone. The mean length of filopodia did not change dramatically, and the mean number of filopodia per growth cone remained constant throughout (data not shown).

To determine whether $\beta 1$ integrin is inserted in the membrane, we performed a similar experiment on cells that had not been permeabilized. After fixing, staining was performed using the W1B10 integrin antibody, which is directed against the extracellular domain of $\beta 1$ integrin (Fig. $3 E$ ). The same pattern of integrin staining was observed both after NGF treatment, when aggregates are at the tips of filopodia, and after subsequent addition of ECM protein (in this case fibronectin), when aggregates migrate rearward along the filopodia.

\section{Pharmacological inhibition of myosin prevents formation of tip aggregates of $\beta 1$ integrin}

The fact that the formation of aggregates of $\beta 1$ integrin at the tips of filopodia in response to NGF is rapid and can occur in previously extended filopodia suggested that it results from the active transport of $\beta 1$ integrin. Because the peripheral region of the growth cone, including filopodia, has an actin cytoskeleton, we thought the accumulation might be myosin-driven. We therefore used BDM, a pharmacological inhibitor of endogenous myosin ATPase activity (Cramer and Mitchison, 1995), to test this possibility. To compare the NGF-mediated formation of tip aggregates of $\beta 1$ integrin with a separate cellular response that might not involve a myosin motor, we adopted the culture procedure used in Figure 1. Thus, we were able to determine the effect of BDM on both the accumulation of tip aggregates and the formation of filopodia. Pretreatment of neurons with $15 \mathrm{~mm}$ BDM for 5 min before the addition of NGF fully blocked the accumulation of $\beta 1$ integrin at the tips of filopodia, whereas the formation of filopodia was only modestly inhibited. $20 \mathrm{~min}$ after the addition of NGF the number of filopodia had increased from $2.5 \pm 2.3$ to $9.2 \pm 2.4$ per growth cone in the presence of BDM, compared with an increase from $1.8 \pm 1.8$ to $14.4 \pm 2.5$ per growth cone in the control. $\beta 1$ Integrin tip aggregates, however, remained at $0.5 \pm 0.7$ per growth cone in the presence of BDM, compared 

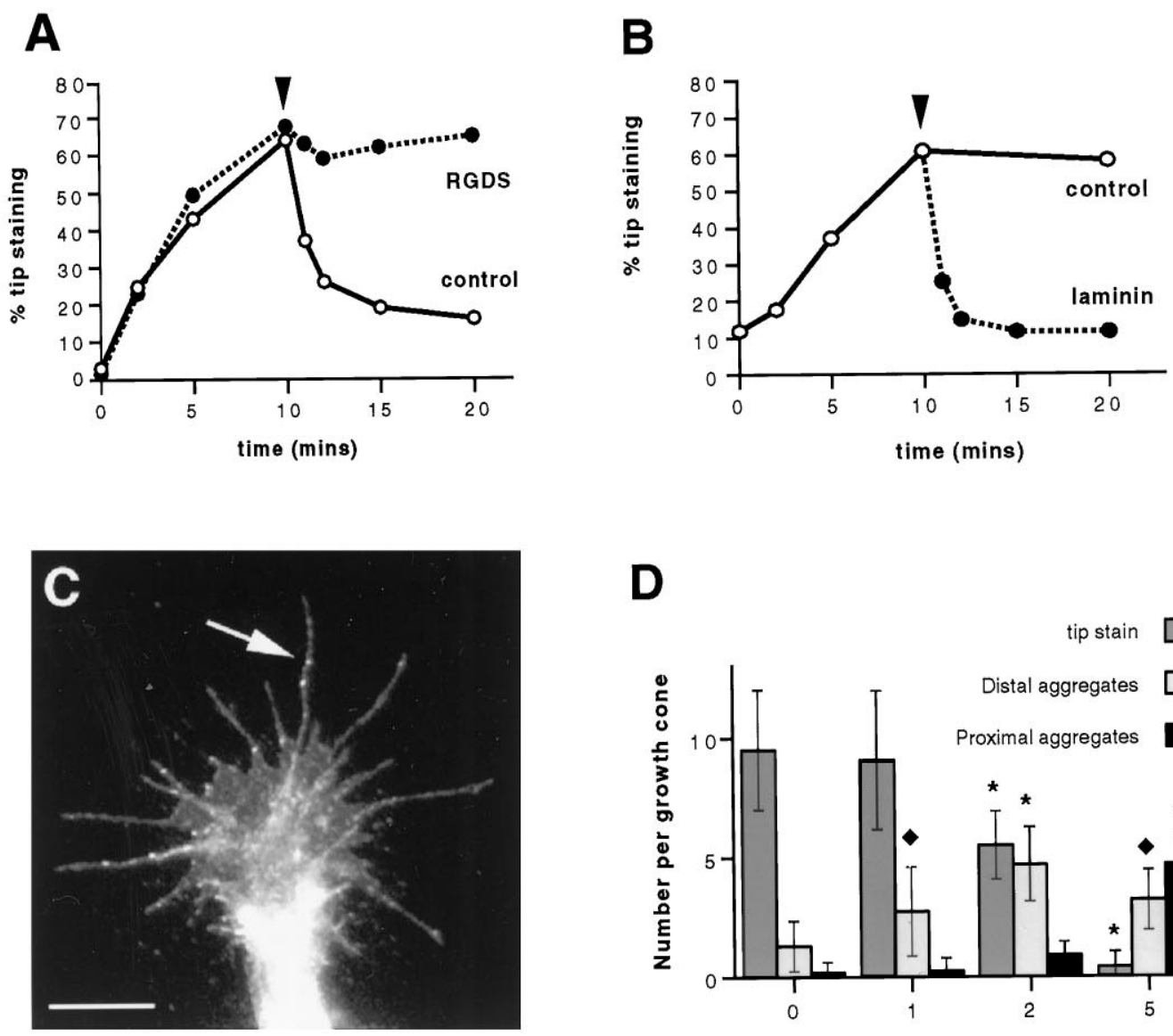

D
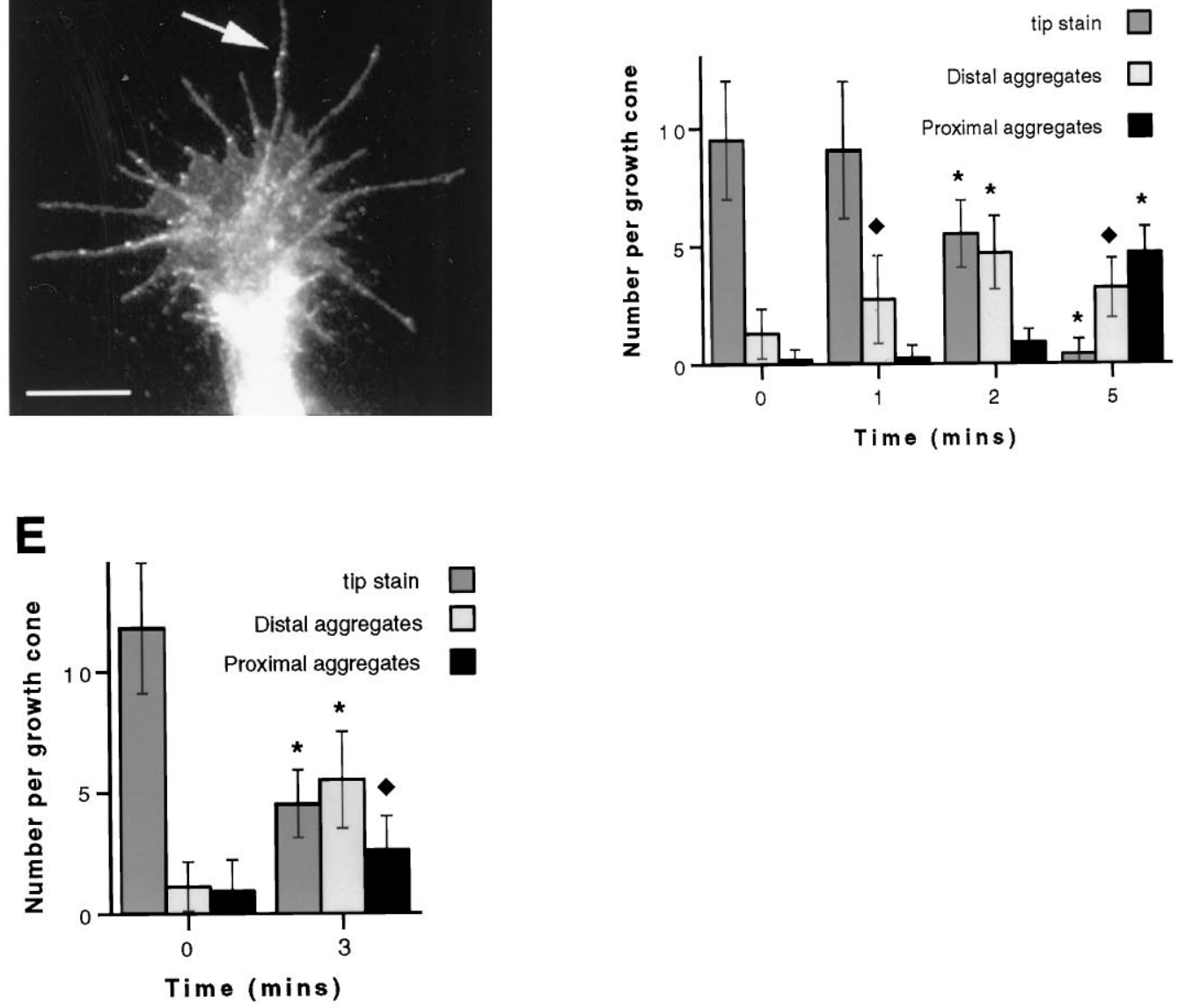

Figure 3. ECM proteins are not necessary for the accumulation of $\beta 1$ integrin at filopodial tips but cause aggregates of $\beta 1$ integrin in growth cones previously treated with $100 \mathrm{ng} / \mathrm{ml}$ NGF to migrate rearward along filopodia. $A$, NGF causes the accumulation of $\beta 1$ integrin tip aggregates ( $0-10$ min) in the presence of $1 \mathrm{mg} / \mathrm{ml} \mathrm{RGDS}$ peptide $(\mathbf{O})$, much the same as NGF alone (O). Addition of $20 \mu \mathrm{g} / \mathrm{ml}$ fibronectin at 10 min (arrowhead) stimulates a rapid decrease in aggregates of $\beta 1$ integrin at filopodial tips in the absence but not the presence of RGDS peptide. Results are representative of three separate experiments $(n=200)$. $B$, Laminin 1 also causes a rapid delocalization of aggregates of $\beta 1$ integrin from filopodial tips when added at a concentration of $20 \mu \mathrm{g} / \mathrm{ml}$ (indicated by the arrowhead). Results are representative of three separate experiments $(n=200)$. $C$, Typical growth cone treated with $100 \mathrm{ng} / \mathrm{ml} \mathrm{NGF}$ for $10 \mathrm{~min}$ followed by $5 \mathrm{~min}$ of treatment with $20 \mu \mathrm{g} / \mathrm{ml}$ laminin 1 . Aggregates of $\beta 1$ integrin, visualized by immunofluorescence staining, can be seen situated along filopodial shafts (arrow). Scale bar, $10 \mu \mathrm{m}$. $D$, Laminin 1 causes rearward migration of aggregates of $\beta 1$ integrin. Cells were treated as in $C$, and filopodia were scored for aggregates of $\beta 1$ integrin at the tips and in the distal (excluding tips) and proximal halves of filopodia. Results are representative of three separate experiments $(n=25)$. $E, \beta 1$ Integrin aggregates are inserted in the membrane while at the tips of filopodia and during rearward migration. Cells were pretreated with NGF for 10 min, followed by 3 min of treatment with fibronectin, surface-stained for $\beta 1$ integrin, and then scored as in $D(n=25)$. In $D$ and $E$, error bars show SDs. Asterisks denote those values that are significantly different $(p<0.005)$ from control $(0 \mathrm{~min})$ values. Diamonds denote those values that are significantly different $(p<0.05)$ from control values. 

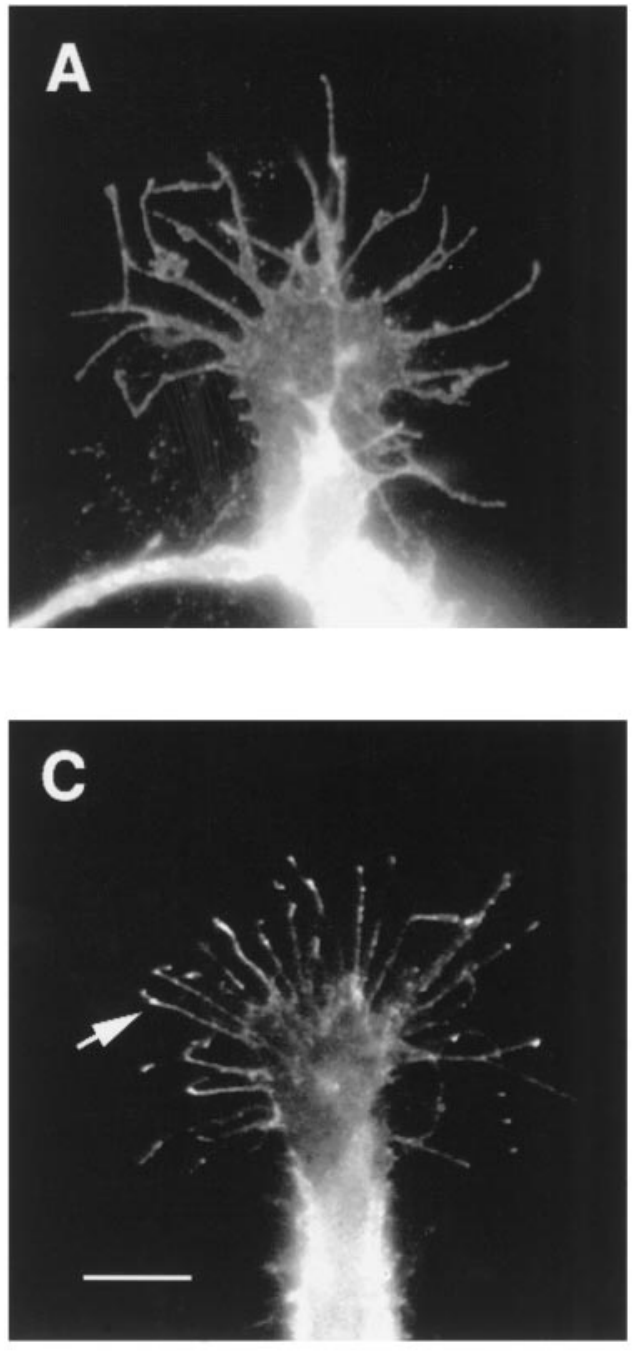
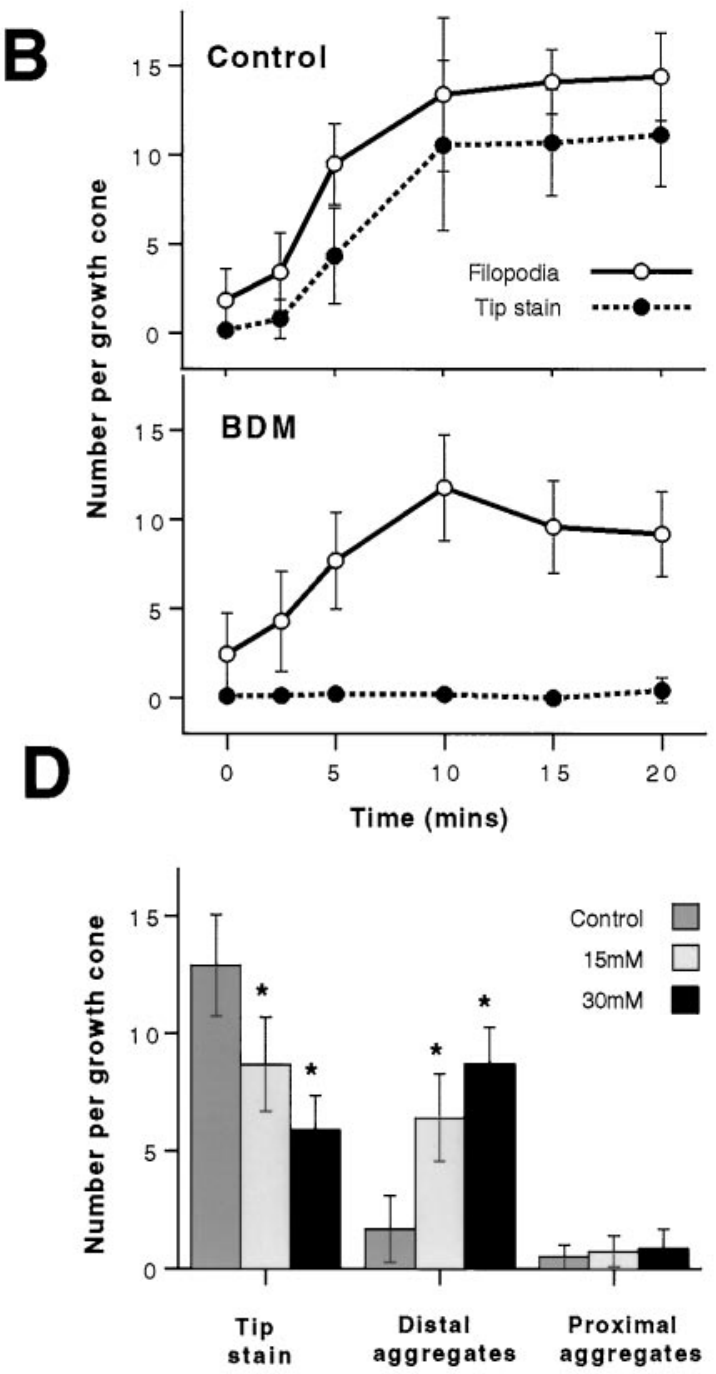

Figure 4. Treatment of cells with $15 \mathrm{~mm}$ BDM for $5 \mathrm{~min}$ before the addition of $100 \mathrm{ng} / \mathrm{ml} \mathrm{NGF}(A, B)$ blocks the accumulation of $\beta 1$ integrin at filopodial tips. $A$, A representative growth cone treated as above and stained for $\beta 1$ integrin has numerous filopodia but no accumulation of $\beta 1$ integrin at filopodial tips. $B$, Counts of filopodia and tip aggregates per growth cone demonstrate that, after treatment with BDM (as in $A$ ), the accumulation of $\beta 1$ integrin at filopodial tips is blocked, but the formation of filopodia is only modestly reduced compared with parallel control cultures (as shown). Error bars show SDs. Results are representative of three separate experiments $(n=100)$. $C, \beta 1$ Integrin aggregates remain either at the tips or in the distal halves of filopodia when $15 \mathrm{~mm}$ BDM is added to cells in which $\beta 1$ integrin had previously accumulated at tips in response to $100 \mathrm{ng} / \mathrm{ml} \mathrm{NGF}$. A typical growth cone shows that the location of most $\beta 1$ integrin aggregates is either at or just behind the tip (arrow) 5 min after the addition of BDM. Scale bar, $10 \mu \mathrm{m}$. $D$, Counts of $\beta 1$ integrin aggregates at either the tip or in the distal (excluding the tip) and proximal halves of filopodia show that, after 5 min of treatment, although BDM causes the number of tip aggregates to decrease, most remain in the distal half of filopodia. Results are representative of three separate experiments $(n=25)$. Error bars show SDs. Asterisks denote those values that are significantly different $(p<0.005)$ from control $(0 \mathrm{~mm})$ values.

with an increase from $0.2 \pm 0.4$ to $11.1 \pm 2.9$ per growth cone without BDM (Fig. $4, A$ and $B$ ). The formation of the early ( $1 \mathrm{~min}$ ) aggregates of $\mathrm{F}$-actin and $\beta 1$ integrin at the leading edge of the peripheral region was, in contrast, observed to occur in the presence of BDM (data not shown).

It is possible that we did not detect tip aggregates of $\beta 1$ integrin not because BDM blocked the forward movement of $\beta 1$ integrin, but rather because it prevented its retention at the tip. Thus, we did another set of experiments in which tip aggregates were allowed to form in response to NGF, and then BDM was added. Figure 4, $C$ and $D$, shows that, although 5 min of treatment with $15 \mathrm{~mm}$ BDM caused a significant reduction in tip aggregates, this was attributable not to a disappearance of aggregates but to a slight shift rearward from the tip. Although tip aggregates decreased from a mean value of $12.9 \pm 2.2$ to $8.7 \pm 2.0$ per growth cone, distal aggregates increased from a mean value of $1.7 \pm 1.4$ to $6.4 \pm 1.8$, and proximal aggregates remained unchanged (Fig. 4D).

\section{DISCUSSION}

These studies of changes in the distribution of $\beta 1$ integrin on the surface of sympathetic growth cones in response to NGF and ECM proteins are significant in two ways. First, they provide evidence of a novel interaction between different types of environmental cues regulating axon growth, one that occurs rapidly at the growth cone. This type of interaction could be important in the turning of growing axons toward the source of a chemoattractant, a means of guidance for which the mechanism is not well understood. Second, in showing that the binding of ligand links the receptor to a motor in the peripheral region of the growth cone, these experiments provide evidence of a particular mecha- 
A
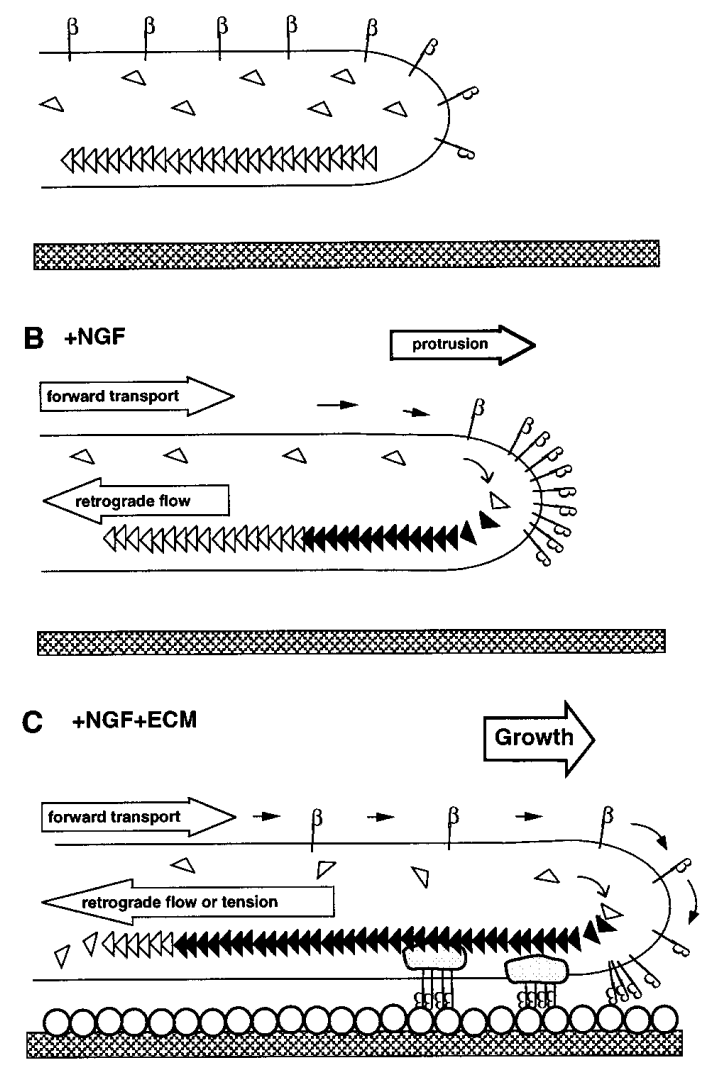

Figure 5. Hypothetical model for the coordinated action of NGF and ECM proteins in a filopodium. $A$, In the quiescent state, $\beta 1$ integrin $(\beta)$ is distributed evenly, and the actin cytoskeleton (open triangles) is static. $B$, NGF induces forward transport of $\beta 1$ integrin to the tip of the filopodium. It also promotes the polymerization of actin, which can lead to protrusion. It is hypothesized that retrograde flow of actin is also stimulated by NGF, but because $\beta 1$ integrin couples to this retrograde flow only in the presence of ECM ligand, $\beta 1$ integrin accumulates at the tip. $C$, In the presence of an ECM substrate (open circles) $\beta 1$ integrin continues to be transported forward. Aggregates located at the tip of the filopodium bind to rearward flowing actin filaments probably via a complex of other proteins (gray shapes) creating tension and/or promoting growth.

nism of axon growth promotion by surface-bound ligands. We discuss these two points below.

\section{A neurotrophin regulates the distribution of a receptor for ECM proteins on the growth cone}

We find that NGF stimulates the rapid accumulation of $\beta 1$ integrin at the tips of growth cone filopodia. Thus, a soluble neurotrophin regulates the distribution of the receptor for ECM proteins, which are typically surface-bound. By regulating the distribution of $\beta 1$ integrin on the growth cone, NGF may regulate the sensitivity of the growth cone to ECM-type ligands. Filopodia are the primary structures of the growth cone for interacting with environmental cues (Bentley and Toroian-Raymond, 1986; Caudy and Bentley, 1986) and thus serve as sensory elements of the growth cone. The tip of the filopodium is not only a favorable site for encountering a cue, as when the grasshopper Ti1 filopodium touches a guidepost cell (Caudy and Bentley, 1986; O'Connor et al., 1990). For $\beta 1$ integrin, at least, it may also be a preferred site for transducing the binding of ligand into effects on the growth cone, because $\beta 1$ integrin attaches to the underlying actin cytoskeleton most readily at the distal edges of the growth cone (Schmidt et al., 1995).

Chemoattraction, the turning of a growing axon toward a diffusible cue, is an important mechanism of guidance in the developing nervous system (Baier and Bonhoeffer, 1994; Goodman, 1996; Tessier-Lavigne and Goodman, 1996). This turning is led by the growth cone, but the mechanism of growth cone turning toward the source is unclear. Orientation of filopodia might be an early event (Gundersen and Barrett, 1980; Zheng et al., 1996). The effect we have described here raises the possibility that the chemoattractant orients receptors for the surface-bound cue that is promoting growth. If the relationship between chemoattractant and surface-bound cue was as described here for NGF and ECM ligands, a gradient of chemoattractant across the growth cone might be expected to concentrate receptors for the surface-bound cue in protrusive structures (filopodia and veils) on one side of the growth cone. These would thus interact more productively with the surface-bound cue than would protrusions on the other side, and the growth cone would turn. An interesting aspect of this mechanism is that the surface-bound cue contributes to guidance while being homogeneously distributed.

\section{NGF causes redistribution of $\beta 1$ integrin in the absence of ECM protein}

NGF affects the distribution of $\beta 1$ integrin without needing the receptor to have bound ECM protein. Accumulation of $\beta 1$ integrin at the tips of filopodia occurred rapidly in serum-free medium on a substrate precoated only with poly-L-lysine (Fig. 2). It is possible that small amounts of ECM proteins were either carried over from tissue dissociation or synthesized in culture. However, the NGF-stimulated accumulation of $\beta 1$ integrin at filopodial tips was not reduced by RGDS peptide (Fig. $3 A$ ), which blocks the interaction of $\beta 1$ integrin with fibronectin and vitronectin. In fact, rather than the tip accumulation of $\beta 1$ integrin being enhanced by addition of ligand for $\beta 1$ integrin (either laminin 1 or fibronectin), it was greatly reduced (Fig. 3). Moreover, binding of fibronectin or laminin in the absence of NGF failed to induce tip accumulation, indicating that there is a requirement for NGF in this process.

Recent work from Hotchin and Hall (1995) and Nobes and Hall (1995) has shown that peptide growth factor can rapidly alter the surface distribution of integrin in fibroblasts. We think the phenomenon we have described here represents a different action of the growth factor, an important distinction being its independence from ligand binding to integrin. Platelet-derived growth factor causes the rapid formation of aggregates of integrin at the periphery of fibroblasts only on a substrate coated with an ECM protein such as fibronectin (Hotchin and Hall, 1995; Nobes and Hall, 1995). In contrast to the tip aggregates we have described here, these "focal complexes" do not form in fibroblasts plated on poly-L-lysine. The focal complex also differs from the tip aggregate in containing high concentrations of several proteins that are found in classic focal adhesions, such as F-actin, paxillin, and vinculin. We do not detect these in appreciable amounts in the tip aggregates (Wu et al., 1996; this paper). Their absence from the tip aggregates probably reflects the requirement for binding of $\beta 1$ integrin to ECM protein to recruit these other proteins into complexes with integrin (Miyamoto et al., 1995a,b). We think that the accumulation of $\beta 1$ integrin at filopodial tips relies on the ability of NGF to stimulate actin-based motility (see below), whereas the formation of focal complexes may not. Thus, the elicitation of focal complexes in fibroblasts is unaffected by cy- 
tochalasin D (Nobes and Hall, 1995), which inhibits actin polymerization and causes F-actin to withdraw rapidly from the peripheral region of the growth cone (Forscher and Smith, 1988), whereas the accumulation of $\beta 1$ integrin at filopodial tips in response to NGF is blocked.

\section{ECM proteins cause rearward migration of $\beta 1$ integrin}

There is a steady rearward flow of actin filaments in the peripheral region of the growth cone (Forscher and Smith, 1988; Okabe and Hirokawa, 1991). It has been suggested that coupling of the substrate to this flow could power advance of the growth cone or at least generate tension within the growth cone (Mitchison and Kirschner, 1988; Goldberg et al., 1991; Lin and Forscher, 1995); recent evidence supports this idea (Lin and Forscher, 1995). Because the actin apparently flows continually rearward at a steady rate, whereas growth and the generation of tension are irregular (Lamoureux et al., 1989), it was suggested that attachment between the actin network and growth cone receptors for substrate-bound molecules is intermittent (Mitchison and Kirschner, 1988; Lin and Forscher, 1995). In fact, $\beta 1$ integrin on the surface of the growth cone and other motile cells is usually not attached to the rearward flow (Schmidt et al., 1995; Felsenfeld et al., 1996).

We present evidence here that the binding of ECM protein to integrin induces linkage to the rearward flow; recently, a similar finding was reported for the lamellipodium of motile fibroblasts (Felsenfeld et al., 1996). Addition of laminin 1 or fibronectin caused aggregates of $\beta 1$ integrin that had formed at filopodial tips in response to NGF to withdraw distoproximally along the filopodia. The withdrawal, which occurs in the plane of the plasma membrane, was dependent on the binding of ECM protein to the receptor, because the RGDS peptide inhibited it. Although we cannot be sure that this rearward movement was mediated by actin, it seems likely. Half of the aggregates had withdrawn several micrometers (far enough to reach the proximal half of the filopodium) within 5 min of addition of ligand, implying a rate of recession in the range of the few micrometers per minute of rearward flow of actin (Lin and Forscher, 1995). Actin is the major cytoskeletal element of the filopodium (Letourneau and Ressler, 1983; Bridgman and Dailey, 1989), and no other mechanism for rearward transport of membrane proteins in the plane of the plasma membrane has been described for the peripheral region of the growth cone or of vertebrate non-neuronal motile cells.

Integrins are thought to work by binding to substrate-bound ligand (Schwartz et al., 1995), as befits receptors that mediate processes such as cell adhesion. Yet we find here that the binding of non-substrate-bound ligand to $\beta 1$ integrin is apparently sufficient to engage the rearward flow mechanism. Some of the laminin 1 or fibronectin that we add in soluble form may well adhere to the substrate, but integrins in the growth cone membrane that bind to these substrate-bound ligand molecules would remain stationary with respect to the substrate rather than moving rearward; that is how tension would be generated. Thus, the integrin molecules we see receding are presumably bound to ligand that is not substrate-bound. Because integrin cross-linking facilitates its interaction with the cytoskeleton (Miyamoto et al., 1995a,b; Felsenfeld et al., 1996), the ability of soluble laminin and fibronectin to induce rearward flow may stem from their binding as a multimer. Consistent with this is the inability of the monomeric ligand RGDS to induce rearward flow when used at a concentration sufficient to occupy many of the receptors (as judged by its ability to block the effect of fibronectin). Whatever the mechanism, the results here provide evidence that substantial signaling through integrin can be induced by soluble ligand.

\section{Mechanism of delivery of $\beta 1$ integrin to the tips of filopodia}

$\beta 1$ Integrin must form the tip aggregates by moving outward along filopodia rather than riding out on the tips of newly forming filopodia, because the appearance of aggregates lagged behind the formation of filopodia and occurred even in preexisting filopodia. The distal edge of the growth cone and the lamellipodium of motile fibroblasts, particularly regions of tightly curved plasma membrane, can retain certain membrane proteins, including $\beta 1$ integrin (Sheetz et al., 1990; Schmidt et al., 1993, 1995), so even diff usion of molecules of $\beta 1$ integrin in the plane of the plasma membrane of the filopodium might result in their accumulation at the tip. In this case, NGF could promote the formation of aggregates by fostering the retention of $\beta 1$ integrin at the tip. We have previously presented evidence suggesting that protein-tyrosine phosphorylation is essential for the maintenance of the tip aggregates (Wu et al., 1996). NGF might promote retention by its ability to stimulate tyrosine phosphorylation (Maher, 1988). Alternatively, $\beta 1$ integrin could reach the tip of the filopodium by directed transport. In this case, NGF could promote the formation of tip aggregates by stimulating this transport or by promoting retention at the tip. Molecules of $\beta 1$ integrin do undergo directed forward movements in the plane of the plasma membrane in the peripheral region of the growth cone (Schmidt et al., 1995). $\beta 1$ Integrin could also be transported within filopodia in membrane-bound vesicles and incorporated into the plasma membrane at the tips by exocytosis, as has been suggested for non-neuronal motile cells (Bretscher, 1996). However, vesicles have not been typically observed in filopodia during observations of living growth cones with video-enhanced contrast differential interference microscopy (Goldberg and Burmeister, 1986; Forscher et al., 1987; Sheetz et al., 1990) or by electron microscopic analysis of fixed specimens (Tosney and Wessells, 1983).

One piece of evidence for the importance of directed transport in the formation of tip aggregates is the action of BDM. Aggregates did not form in the presence of this drug. Clearly, BDM interfered with the delivery, but not the retention, of $\beta 1$ integrin, because aggregates were retained at or near the tip when BDM was added after their formation. Because F-actin is the major cytoskeletal constituent of the peripheral region of growth cones and non-neuronal motile cells and myosins are the only known actin-activated motor proteins, myosin is the prime candidate for a transport motor in this region. The directed forward transport in the plane of the plasma membrane of certain proteins in growth cones was suggested to be powered by a myosin (Sheetz et al., 1990). BDM strongly inhibits actin-activated ATPase activity of some, and perhaps many or all, myosins (Cramer and Mitchison, 1995). It is effective when applied to intact cells; for example, it has been used to show an involvement of myosin in powering the rearward flow of F-actin in the peripheral region of the growth cone (Lin et al., 1996). It does not inhibit actin polymerization or disrupt actin filaments (Cramer and Mitchison, 1995; Lin et al., 1996); the present results showing nearly normal NGF-induced growth of filopodia in the presence of BDM confirm that. Although the inhibition of tip accumulation by BDM suggests an involvement of myosin, additional work will be needed to confirm this, because BDM may not be completely 
specific for myosins. (Zhu and Ikeda, 1993; Sellin and McArdle, 1994).

\section{A cycle for $\beta 1$ integrin in the growth cone}

The present results, in the context of previous work discussed above, are consistent with the hypothetical scheme depicted in Figure 5. In this scheme, based on previous models of actin flow (Mitchison and Kirschner, 1988; Goldberg et al., 1991; Lin and Forscher 1995), there is a cycle in which $\beta 1$ integrin is transported to the distal edge (in the case under study, the tips of filopodia) and binds ligand, which causes the integrin to link to the underlying network of actin filaments, which flows steadily rearward. If the ligand is surface-bound, as is typical with ligands for $\beta 1$ integrin and as depicted in Figure 5, tension can be generated. Also, an advancing growth cone will grow over the immobilized integrin. If the ligand is soluble, the integrin will move rearward along the filopodium, as seen in the present experiments. In this scheme, both the forward and rearward transport of $\beta 1$ integrin are powered by actomyosin, although different species of myosin may be involved in the two movements. The forward transport and probably the rearward as well are stimulated by NGF. The key difference is that binding of ligand to $\beta 1$ integrin is required for efficient coupling to the rearward, but not the forward, transport. Thus, NGF turns on the transport machinery, whereas the ECM protein is a coupling switch.

\section{REFERENCES}

Aletta JM, Greene LA (1988) Growth cone configuration and advance: a time-lapse study using video-enhanced differential interference contrast microscopy. J Neurosci 8:1425-1435.

Baier H, Bonhoeffer F (1994) Attractive axon guidance molecules. Science 265:1541-1542.

Bandtlow C, Zachleder T, Schwab ME (1990) Oligodendrocytes arrest neurite growth by contact inhibition. J Neurosci 10:3837-3848.

Baron-van Evercooren A, Kleinman HD, Ohno S, Marangos P, Schwartz JP, Dubois-Dalq ME (1982) Nerve growth factor, laminin and fibronectin promote nerve growth in human fetal sensory ganglia cultures. J Neurosci Res 8:179-183.

Bentley D, Toroian-Raymond A (1986) Disoriented pathfinding by pioneer neurone growth cones deprived of filopodia by cytochalasin treatment. Nature 323:712-715.

Bixby JL, Lilien J, Reichardt LF (1988) Identification of the major proteins that promote neuronal process outgrowth on Schwann cells in vitro. J Cell Biol 107:353-361.

Bozyczko D, Horwitz AF (1986) The participation of a putative cell surface receptor for laminin and fibronectin in peripheral neurite extension. J Neurosci 6:1241-1251.

Bretscher MS (1996) Moving membrane up to the front of migrating cells. Cell 85:465-467.

Bridgman PC, Dailey ME (1989) The organization of myosin and actin in rapid frozen nerve growth cones. J Cell Biol 108:95-109.

Caudy M, Bentley D (1986) Pioneer growth cone steering along a series of neuronal and non-neuronal cues of different affinities. J Neurosci 6:1781-1795.

Coates TD, Watts RG, Hartman R, Howard TH (1992) Relationship of F-actin distribution to development of polar shape in human polymorphonuclear neutrophils. J Cell Biol 117:765-774.

Cramer LP, Mitchison TJ (1995) Myosin is involved in postmitotic cell spreading. J Cell Biol 131:179-189.

Duband J-L, Nuckolls GH, Ishihara A, Hasegawa T, Yamada KM (1988) Fibronectin receptor exhibits high lateral mobility in embryonic locomoting cells but is immobile in focal contacts and fibrillar streaks in stationary cells. J Cell Biol 107:1385-1396.

Felsenfeld DP, Choquet D, Sheetz MP (1996) Ligand binding regulates the directed movement of $\beta 1$ integrin on fibroblasts. Nature 383:438-440.

Forscher P, Smith SJ (1988) Actions of cytochalasins on the organization of actin filaments and microtubules in a neuronal growth cone. J Cell Biol 107:1505-1516.

Forscher P, Kaczmarek LK, Buchanen JA, Smith SJ (1987) Cyclic AMP induces changes in distribution and transport of organelles within growth cones of Aplysia bag cell neurons. J Neurosci 7:3600-3611.

Goldberg DJ, Burmeister DW (1986) Stages in axon formation: observations of growth of Aplysia axons in culture using video-enhanced contrast-differential interference microscopy. J Cell Biol 103:1921-1931.

Goldberg DJ, Burmeister DW, Rivas RJ (1991) Video microscopic analysis of events in the growth cone underlying axon growth and the regulation of these events by substrate-bound proteins. In: The nerve growth cone (Letourneau PC, Kater SB, Macagno ER, eds), pp 79-95. New York: Raven.

Goodman CS (1996) Mechanisms that control growth cone guidance. Annu Rev Neurosci 19:341-377.

Gundersen RW, Barrett JN (1980) Characterization of the turning response of dorsal root neurites towards NGF. J Cell Biol 87:546-554.

Hammarback JA, Letourneau PC (1986) Neurite extension across regions of low cell-substratum adhesivity: implications for the guidepost hypothesis of axonal pathfinding. Dev Biol 117:655-662.

Hotchin NA, Hall A (1995) The assembly of integrin adhesion complexes requires both extracellular matrix and intracellular rho/rac GTPases. J Cell Biol 131:1857-1865.

Hynes RO (1992) Integrins: versatility, modulation, and signaling in cell adhesion. Cell 69:11-25.

Kapfhammer JP, Raper JA (1987) Collapse of growth cone structure on contact with specific neurites in culture. J Neurosci 7:201-212.

Lamoureux P, Buxbaum RE, Heidemann SR (1989) Direct evidence that growth cones pull. Nature 340:159-162.

Letourneau PC, Ressler AH (1983) Differences in the organization of actin in the growth cones compared with the neurites of cultured neurons from chick embryos. J Cell Biol 97:963-973.

Levi-Montalcini R (1987) The nerve growth factor 35 years later. Science 237:1154-1162.

Lin C-H, Forscher P (1995) Growth cone advance is inversely proportional to retrograde F-actin flow. Neuron 14:763-771.

Lin C-H, Espreafico EM, Mooseker MS, Forscher P (1996) Myosin drives retrograde F-actin flow in neuronal growth cones. Neuron 16:769-782.

Loeb DM, Maragos J, Martin-Zanca D, Chao MV, Parada LF, Greene LA (1991) The trk proto-oncogene rescues NGF responsiveness in mutant NGF-nonresponsive PC12 cell lines. Cell 66:961-966.

Maher, PA (1988) Nerve growth factor induces protein-tyrosine phosphorylation. Proc Natl Acad Sci USA 85:6788-6791.

Mitchison TJ, Kirschner M (1988) Cytoskeletal dynamics and nerve growth. Neuron 1:761-772.

Miyamoto S, Akiyama SK, Yamada KM (1995a) Synergistic roles for receptor occupancy and aggregation in integrin transmembrane function. Science 267:883-885.

Miyamoto S, Teramoto H, Coso OA, Gutkind JS, Burbelo PD, Akiyama SK, Yamada KM (1995b) Integrin function: molecular hierarchies of cytoskeletal signaling molecules. J Cell Biol 131:791-805.

Nobes CD, Hall A (1995) Rho, rac, and cdc42 GTPases regulate the assembly of multimolecular focal complexes associated with actin stress fibers, lamellipodia, and filopodia. Cell 81:53-62.

O'Connor TP, Duerr JS, Bentley D (1990) Pioneer growth cone steering decisions mediated by single filopodial contacts in situ. J Neurosci 10:3935-3946.

Okabe S, Hirokawa N (1991) Actin dynamics in growth cones. J Neurosci 11:1918-1929.

Reichardt LF, Tomaselli KJ (1991) Extracellular matrix molecules and their receptors: functions in neural development. Annu Rev Neurosci 14:531-570.

Rivas RJ, Burmeister DW, Goldberg DJ (1992) Rapid effects of laminin on the growth cone. Neuron 8:107-115.

Rogers SL, Letourneau PC, Palm SL, McCarthy J, Furcht LT (1983) Neurite extension by peripheral and central nervous system neurons in response to substrate-bound fibronectin and laminin. Dev Biol 98:212-220.

Rogers SL, Edson KJ, Letourneau PC, McLoon SC (1986) Distribution of laminin in the developing nervous system of the chick. Dev Biol 113:429-435.

Schmidt CE, Horwitz AF, Lauffenburger DA, Sheetz MP (1993) Integrin-cytoskeletal interactions in migrating fibroblasts are dynamic, asymmetric, and regulated. J Cell Biol 123:977-991.

Schmidt CE, Dai J, Lauffenburger DA, Sheetz MP, Horwitz AF (1995) Integrin-cytoskeletal interactions in neuronal growth cones. J Neurosci 15:3400-3407. 
Schwartz MA, Schaller MD, Ginsberg MH (1995) Integrins: emerging paradigms of signal transduction. Annu Rev Cell Biol 11:549-599.

Seeley PJ, Greene LA (1983) Short latency actions of nerve growth factor at the growth cone. Proc Natl Acad Sci USA 80:2789-2793.

Sellin LC, McArdle JJ (1994) Multiple effects of 2,3-butanedione monoxime. Pharmacol Toxicol 74:305-313.

Sheetz MP, Baumrind NL, Wayne DB, Pearlman AL (1990) Concentration of membrane antigens by forward transport and trapping in neuronal growth cones. Cell 61:231-241.

Tessier-Lavigne M, Goodman CS (1996) The molecular biology of axon guidance. Science 274:1123-1133.

Tomaselli KJ, Damsky CH, Reichardt LF (1987) Interactions of a neuronal cell line (PC12) with laminin, collagen IV, and fibronectin: identification of integrin-related glycoproteins involved in attachment and process outgrowth. J Cell Biol 105:2347-2358.

Tomaselli KJ, Hall DE, Flier LA, Gehlsen KR, Turner DC, Carbonetto S, Reichardt LF (1990) A neuronal cell line (PC12) expresses two $\beta 1$-class integrins- $\alpha 1 \beta 1$ and $\alpha 3 \beta 1$-that recognize different neurite outgrowth-promoting domains in laminin. Neuron 5:651-662.
Tosney KW, Wessells NK (1983) Neuronal motility: the ultrastructure of veils and microspikes correlates with their motile activities. J Cell Sci 61:389-411.

Wallenstein S, Zucker CL, Fleiss JL (1980) Some statistical methods useful in circulation research. Circ Res 47:1-9.

Wu D-Y, Wang L-C, Mason CA, Goldberg DJ (1996) Association of $\beta 1$ integrin with phosphotyrosine in growth cone filopodia. J Neurosci 16:1470-1478.

Zhang Z, Tarone G, Turner DC (1993) Expression of integrin alpha 1 beta 1 is regulated by nerve growth factor and dexamethasone in PC12 cells. Functional consequences for adhesion and neurite outgrowth. J Biol Chem 268:5557-5565.

Zheng JQ, Wan JJ, Poo M (1996) Essential role of filopodia in chemotropic turning of nerve growth cone induced by a glutamate gradient. J Neurosci 16:1140-1149.

Zhu Y, Ikeda SR (1993) 2,3-Butanedione monoxime blockade of $\mathrm{Ca}^{2+}$ currents in adult rat sympathetic neurons does not involve "chemical phosphatase" activity. Neurosci Lett 155:24-28. 